\title{
Monetised childhoods: Money and consumption among young weavers in Addis Ababa, Ethiopia
}

Global Studies of Childhood

$1-12$

(C) The Author(s) 2019

Article reuse guidelines: sagepub.com/journals-permissions DOI: 10.1।77/2043610619895021 journals.sagepub.com/home/gsc

\author{
Fasil Nigussie Taye iD \\ Addis Ababa University, Ethiopia
}

\section{Roy Huijsmans}

Erasmus University Rotterdam, The Netherlands

\begin{abstract}
In this article, we bring to the foreground an understudied dimension of working children's lives in the Global South: their access to money and the consumption this facilitates. Drawing on life history interviews, we show that among the Gamo weavers of Ethiopia, the modern phenomenon of a monetised childhood is at least six decades old and an element of the informal apprenticeships through which Gamo children learn to weave. Qualitative research with young weavers shows that both girls and boys become involved in weaving. Yet the amount of senbeta misa money they receive differs substantially, fuelling distinctly different consumption practices and reinforcing broader gender relations. Zooming in on boys' monetised leisure activities, we furthermore argue that through consumption belonging to age-based, ethnic peer groups is realised. Moreover, while the monetisation of leisure is shaped by globalisation and market forces, we show that boys and young men themselves also actively contribute to the monetisation of their leisure activities and thereby transform the nature of play.
\end{abstract}

\section{Keywords}

childhood, consumption, gender, money

\section{Childhood, money and consumption between the Global North and South}

Children's relation with money and consumption is a contested issue. Based on research in the Global North, Daniel Cook (2005: 156) attributes this to a hegemonic construct of childhood which assumes 'a fundamental, original separation of children from commerce'. The role of money in 
children's consumption adds another layer of complexity. Drawing on Bloch and Parry's seminal work on money and morality, Minna Ruckenstein (2010: 398) writes that 'according to western ideology, money disrupts and even destroys social relations'. She further adds that adults' concerns about children's use of money stems from a fear that this might destroy 'the essence of childlike activities by introducing forces that threaten them' (Ruckenstein, 2010: 399).

For some decades now, recognising children's agency has been a key characteristic of childhood studies (Huijsmans, 2016: 1). Yet, in relation to consumption, such agency is exercised in a field shaped by powerful commercial actors, often specifically targeting children. Based on research in the United States of America, McNeal has explained such commercial interest in children by pointing out that children constitute a market in a triple sense: a primary market with its own spending power, an influence market shaping the consumption of their parents and as a future market (McNeal, 1999 in Zelizer, 2002: 378). Commerce is thus a force to be reckoned with in understanding children as consumers, something that also holds true for the Global South (Huijsmans and Trân, 2015). A first step towards recognising children's agency as consumers and the powerful commercial forces shaping consumption practices is to stop treating children and commerce or play and market exchange as separate realms. Rather, we need to acknowledge that money and consumption constitute dimensions of childhood as much as play and learning do (Huijsmans, 2016: 12). The phrase 'monetised childhoods' we use in this article to draw attention to the way in which money and consumption play a role in what it means to be a child and how through their everyday consumption practices children construct particular (monetised) childhoods.

In the Global North, childhood scholars have started paying attention to children as consumers and the meaning of money and consumption in children's everyday lives (e.g. Cook, 2008; Pugh, 2011; Ruckenstein, 2010; Zelizer, 2002). Yet, such work is virtually absent from research with children in the Global South (a notable exception is Chee, 2000). Even Deborah Levison's (2000) seminal article on Children as economic agents makes hardly any mention of children as consumers.

The silence on children as consumers in the Global South is surprising because studies with working children conducted in various countries are replete with casual references to children's engagement with money (for an early example, see White, 1996: 830). These references often do not give us deep insight in children's consumption in the Global South, but collectively they make the important point that more widespread levels of relative and absolute poverty do not mean that money and consumption have no role to play in young lives in the Global South - quite the contrary! Even if children's work is largely survival motivated, this does not exclude them from engaging in consumption practices for leisure purposes. By focusing on the role of consumption in children's lives in the context of urban Ethiopia, we respond to Viviana Zelizer's (2002: 393) call for expanding research on children's economic relations beyond the Global North 'towards the enormous variety of children's circumstances in the lower income regions where most of the world's children actually live'.

Noticeably, silence on children's actual engagement with money in the Global South is also maintained by actors we would least expect it from. The case in point is interventions around the theme of 'financial inclusion'. For example, publications coming out of the Child and Youth Finance Movement (e.g. Billimoria et al., 2013) advocate for including children in the Global South in formal financial institutions and practices but do so without acknowledging that in the Global South, too, childhoods are already monetised and that children are already actively taking part in all sorts of financial practices as part of their everyday lives.

Tatek Abebe and Yaw Ofosu-Kusi's (2016) work on African childhoods goes some way towards explaining these different foci between childhood research in the Global North and South. They argue that African childhoods remain predominantly represented as either in crisis or 'removed 
from forces of modernity, infrastructures and technology' (Abebe and Ofosu-Kusi, 2016: 304). Such constructs contribute to a state of affairs in which children's engagement with money in the Global South has received little attention beyond research with working children, and even then, the assumption is often that the money earned is used for survival predominantly. The latter is in line with a broader trend observed by Payal Arora (2019). She argues that social science scholarship in the Global South struggles to fully acknowledge consumption for leisure purposes among the poor. Yet, as the quote below from a young snack vendor in Ethiopia illustrates, also in the African context children aspire to leisure. Yet, in the African context, too, this typically requires money because many forms and places of leisure are monetised:

I feel happy when I get the chance to watch TV in bars and also sell . . When I see a person with his money being drunk and losing himself I laugh . . . We feel happy when a customer comes along smiling. (Woodhead, 1999: 40)

In this article, we focus on the role of money in the lives of working children involved in the traditional weaving economy in Addis Ababa, Ethiopia. We show that young weavers' access to money facilitates new globalised forms of consumption among the young (e.g. watching European football matches), while it also transforms existing, localised forms of play (e.g. adding a 'betting' element to childhood games). We further argue that the modern phenomenon of money has long played a role in the process of becoming a young weaver as it is an element of a traditional (and gendered) apprenticeship practice. As such, we argue that Gamo childhoods have long been monetised. Even so, the forms of consumption this has facilitated have changed over time and thereby the particular ethnic, gendered and age-based distinctions that are realised through consumption (see also Huijsmans, 2019: 6).

The next section describes the study context and the research methodology. Thereafter, Gamo children's access to money through the practice of senbeta misa is introduced as well as the longstanding informal apprenticeship system it is part of. In the data and analysis section, we present both quantitative and qualitative data on the gendered dimensions of Gamo children's access to senbeta misa money and the forms of leisure consumption they engage in. We also explain how the introduction of money transforms play and how in this way subtle forms of distinctions are enacted.

\section{Context and methodology}

For this article, we draw on research conducted by the first author in two localities in Gulele subcity which is part of Addis Ababa, Ethiopia's capital. Addis Ababa's informal weaving economy is concentrated in Gulele sub-city, making it an appropriate site for studying working children's engagement with money and their consumption practices. Coming of age in Gulele sub-city constitutes a radically different experience than growing up in the more remote and rural parts of the country. For example, the relative isolation from market forces and global modernity described by Tadesse Jaleta Jirata (Jirata, 2019) for the agro-pastoralist Guji people of southern Ethiopia stands in stark contrast with how children and youth grow up in urban Ethiopia. As this article illustrates, Gulele sub-city is a space of production and consumption and both dynamics are fully integrated in the (global) cash economy. The money generated through weaving sustains the numerous tea rooms, local cinemas and retail shops in Gulele sub-city and gives Gulele sub-city an urban buzz.

The fieldwork in Gulele sub-city was conducted over a year between November 2015 and October 2016 as part of a PhD study (see Taye, 2019). The interviews were conducted in Amharic, which is the mother tongue of the first author and proved no obstacle for Addis Ababa-based ethnic Gamo. The interview transcripts were later transcribed and translated into English. For this article, 
we draw primarily on material from interviews with a total of 40 young weavers aged 11-18 (28 males and 12 females). We put the contemporary practice in historical perspective by presenting material from life history interviews with elderly, former weavers. In an attempt to somewhat unsettle the vast differences due to different ethnic background, class position, age and at times gender, the first author has taken it upon him to learn the basics of weaving from young Gamo weavers. It was through such forms of participant observation that a deeper insight was gained into what it means to be young, Gamo and weaving. Next to participating in the work of weaving, the first author also conducted participant observation in young weavers' leisure sites including street corners, the home, tea rooms and local cinemas.

During fieldwork, the key ethical issues in research with children were respected including securing the oral consent of all interviewees, including children, and ensuring anonymity (see Taye, 2019). To protect the identity of the research participants (adult and child alike), all names presented in this article are pseudonyms.

\section{Gamo, weaving and senbeta misa}

The Addis Ababa traditional weaving sector is dominated by weavers from the Gamo ethnic group. Gamo people originate from the Gamo highlands in South-western Ethiopia. Mobility between the rural Gamo highlands and Addis Ababa is widespread, but by now, many Gamo families have also settled permanently in parts of Addis Ababa where they have established themselves in the weaving economy.

Despite government efforts to stimulate the relocation of weaving work away from households and into newly established factories, most weaving of traditional fabric remains household based. Within the household, the work of weaving is organised through an intricate division of labour shaped by the intersecting dynamics of gender and age. From a young age (around the age of 7), children get involved in activities such as spinning and twisting shawl, and in their early teenage years, they start learning basic weaving activities. Yet, the transition through the various skills of weaving is strongly gendered. Few girls end up becoming independent weavers, most continue into adulthood doing supplementary tasks only such as spinning.

Over recent years, children's involvement in the traditional weaving sector has attracted considerable attention. The work of weaving has been listed by the Ethiopian authorities as one the worst forms of child labour, and migration for work of Gamo children and youth from the Gamo highlands to the Addis Ababa has been presented as a form of human trafficking (see Taye, 2019: 139-143). In such a discursive environment, there is little space to appreciate that children's involvement in the work of weaving also constitutes a form of learning. Indeed, young Gamo's awareness that educational qualifications do not necessarily lead to employment means that numerous Gamo children and youth consciously combine schooling with weaving. For these children and youth, early involvement in weaving constitutes an apprenticeship through which they acquire marketable skills that schools cannot offer (Taye, 2019).

The phrase senbeta misa refers to the money children receive as part of their involvement in the work of weaving. Senbeta misa can be translated as Sabbath Lunch. ${ }^{1}$ It is male master weavers who sell the fabrics at weekly markets. Part of the proceeds of this sale the master weaver gives to children and youth who have contributed to the work in the preceding week. Senbeta misa money is generally given on a Sunday (hence the phrase 'sabbath/Sunday lunch'), because it is over the weekend that weavers sell their produce. Master weavers give senbeta misa both to their own children if they have contributed to the weaving work, as well as to children who have come from the rural Gamo highlands and live with the household to acquire the skill of weaving (compare with Chea and Huijsmans, 2018). 
The young weavers distinguish the money they receive as senbeta misa from the salary earned by a skilled weaver. For example, when the first author asked a 16-year-old male weaver who worked for his older brother whether he also received senbeta misa he insisted that the money he got for his work was not senbeta misa, but eij kiray (i.e. salary and literally meaning 'hiring skilful hands for wages'). The verbs used in relation to senbeta misa also underscore this distinction. Rather than talking about 'earning' (tekefelegn in Amharic) children would talk about 'receiving' (tesetegn) senbeta misa. Similarly, master weavers would speak of 'giving' (setehu) senbeta misa rather than 'paying' (kefelku in Amharic) it.

\section{Senbeta misa: of modernity and tradition}

Gamo children's access to money through senbeta misa can be traced back several decades. Among the Gamo, it may thus be argued that the modern phenomenon of 'monetised childhoods' is not something new. Various older informants claimed that receiving senbeta misa money was already an established practice in the 1950s, just years after the introduction of modern paper money in Ethiopia in 1946 (Degefe, 1995). For example, Gash Berhanu (a 74-year-old former weaver at the time of interview) recalls that he started to work as a spinner in the mid-1950s and progressed into weaving around age 12 at his uncle's workplace in Addis Ababa. He claims that his uncle would give him senbeta misa every Sunday (Field notes, 29 July 2016).

Mamo a 45-year-old male weaver explains that he migrated from the rural Gamo highlands in the early 1980s. In Addis Ababa, he moved into his uncle's household and learnt to weave. Next to his involvement in weaving, he lamented that his uncle also ensured he attended school and gave him 0.50 birr as senbeta misa every Sunday. Mamo claimed that the amount of money he received exceeded what his non-weaving peers could earn at the time through various other activities such as shoe-shining. This allowed him to spend more money on social activities, which, he argued, increased his status among his peers (Interview notes, 12 December 2015).

Older respondents explained that back in the days the practice of senbeta misa would even encourage some male Gamo youth to migrate to Addis Ababa. For example, Gash Abate recalls that in the 1950s, he saw his peers coming back from Addis Ababa wearing shoes and styles of clothing he had never seen before. Attracted by this display of modernity facilitated through the consumption power of senbeta misa he, too, left the Gamo highlands to become a young weaver in Addis Ababa (Field notes, 13 July 2016).

These historical details show that the work of weaving, access to money and independent consumption have long been distinctive features of Gamo childhood, and especially Gamo boyhood. To date, this is still the case. The excerpt below from an interview with a 14-year-old Gamo boy named Biniam shows that access to senbeta misa money works as an important social distinction for Gamo childhoods in urban Addis Ababa. It also shows that, of course, not all Gamo children weave, or do so permanently during their childhood:

Fasil: $\quad$ How much 'senbeta misa' you get?

Biniam: I do not receive that.

Fasil: Why not?

Biniam: Because I do not need it. In the past, I used to receive some but not anymore.

Fasil: $\quad$ You do not eat outside or play with friends?

Biniam: All my friends are Amhara ${ }^{2}$ who do not weave and do not know so-called 'senbeta misa'.

Fasil: $\quad$ Are you saying your Amhara friends do not receive money from their parents?

Biniam: Yeah 
Fasil: What about fellow Gamo friends in the village?

Biniam: They receive 'senbeta misa' because of weaving.

(Interview excerpt, Addis Ababa, 21 September 2016)

\section{Money, age and gender}

Based on interview material and field notes, it is possible to establish that out of the 40 child weavers (28 male, 12 female) who participated in the research, 36 reported regularly receiving senbeta misa. Among the remaining four (all male), three worked for themselves and lived independently, and the other one is the 14-year-old boy named Biniam referred to above who does no longer receive senbeta misa on a regular basis. As the excerpt in the above section illustrates, Biniam did not need cash at the moment of interview because his peers were from other ethnic groups who normally did not spend money when socialising. In addition, since Biniam's socialised mostly with non-Gamo children, his claim that he does not need money may also be influenced by the common expression in Ethiopia that 'money is not good for children' (in Amharic: genzeb leligoch tiru ayidelem).

In Figure 1, we plot the weekly amounts of senbeta misa received by young apprentice weavers by age and gender. ${ }^{3}$ The data show that overall girls and young women receive a smaller amount of senbeta misa than their male peers do, even though they certainly did not work fewer hours. The difference is substantial: among the 11 girls receiving senbeta misa on a weekly basis, the amount varied from 5 to 50 birr with a median of 27.50 birr (approximately $1.25 \mathrm{Euro}^{4}$ ), while for the boys, the amount varied from 25 to 200 birr with a median of 115 birr (approximately 5 Euros). Fifteenyear-old Askale is an exception. She receives 30 birr per week, which is more than some boys at this age and also more than some of the older girls. This can be explained because Askale is more skilled than many other young female weavers and able to weave duvets ( $\mathrm{gabi}$ ), and among Gamo weavers, the amount of senbeta misa that young people receive increases with age and skill levels. Askale's skill level is probably higher than that of many other young women because she is the main breadwinner in the family and therefore has gone beyond doing supplementary weaving activities.

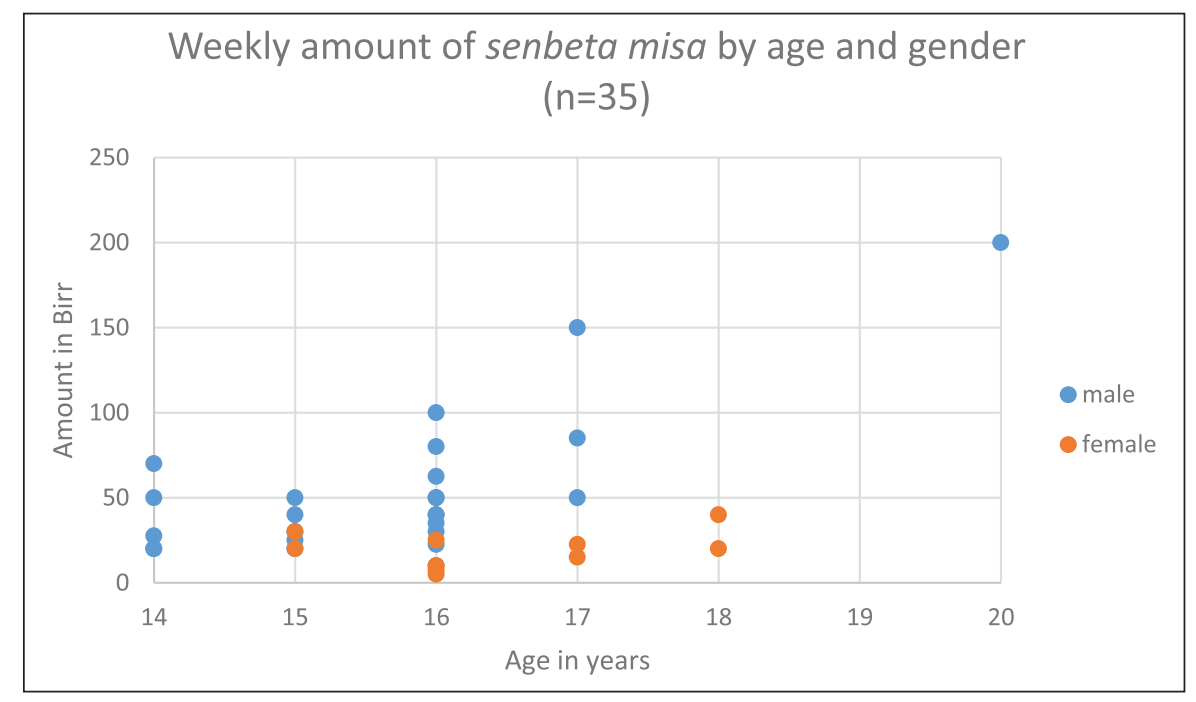

Figure I. Weekly amount of senbeta misa by age and gender. 
Figure 1 further shows a pattern of the amount of senbeta misa increasing with age. This is not a perfect pattern, though. For example, two 14-year-old boys receive amounts of senbeta misa larger than some of their 15- and 16-year-old peers. Both of these boys were working in their own households. In addition, these relatively higher amounts of senbeta misa can be explained because one of the boys is able to weave patterns (tilet) which is a higher valued skill than weaving plain fabric. The other boy is one of the few children who expressed unhappiness about his work because his father makes him work too much (producing about $40 \mathrm{~m}$ of fabric per week).

When asked, girls and boys expressed awareness of gender differences in the amount of senbeta misa they received and attributed it to differences in skill. Although we found skill differences by gender, it is important to acknowledge that this is due to a gendered division of labour and not because of any inherent differences between boys and girls in the ability to acquire weaving skills. The gender division of labour is such that boys are introduced into the more socially valued work of weaving and girls typically do not progress beyond the less socially valued supplementary activities such as spinning.

Gender differences in the amount of senbeta misa can also be explained in relation to how money is associated differently with girlhood as opposed to boyhood. For example, a 14-year-old young male weaver who received 50 birr every week insisted that the amount was peanuts by acclaiming '50 birr Min alat?'5 (What is 50 birr after all?; Interview quotes, Addis Ababa, 13 August 2016). In comparison, only one of the girls (18 years old) reported ever receiving a 50 birr amount of senbeta misa. When asked, she explained that she sometimes asked for 'the maximum'. Although she is aware of the substantially larger amounts of senbeta misa young men receive, she considers this out of her scope. In contrast, a 16-year-old female weaver who received 10 birr justified this relatively small amount by saying 'money is not good for a child like me'. Similarly, another 16-year-old girl explained that 'I get around 10 birr and I don't want more than that'. These examples indicate that the normative idea that money and childhood is a bad combination, as already introduced above, bears more heavily on girls and young women than it does on their male peers. One strategy around this is for girls to not keep the money themselves. This is indeed what one 18-year-old young female weaver did who received a relatively large amount of senbeta misa. She explained 'the money stays with my family for a long time and I take it once and get up to 700 birr in several months'. Because the cash is not channelled to her directly, she can receive larger amounts of money without disrupting the image that 'money is not good for a (girl) child'.

\section{Consumption}

\section{Gender}

Gender not only shapes the amount of senbeta misa boys and girls receive, as a social relation gender also shapes consumption practices. First, boys and young men commonly spend their senbeta misa money away from home by hanging out with friends on the street, in local cinemas and youth centres, and in local restaurants and teashops. Second, boys and young men tend to spend their senbeta misa money on individual consumption goods such as mobile phones which were especially sought after among the young male weavers in the 15 to 18 age group. In contrast, none of the young female weavers mentioned spending any of their senbeta misa money on food in restaurants and they would also refrain from entering the predominantly male social spaces such as cinemas and youth centres. Indeed, when discussing the use of senbeta misa money with Zenebech (17-year-old doing spinning work) she was quick to say that young women like her would not enter local cinemas (video bets) or youth centres. These are not places for girls she claimed (Field notes: Addis Ababa, 23 July 2016). 
Girls and young women explained that they used their senbeta misa money mostly for saving, would give it to their mothers, would use it for buying clothes and shoes, or for buying sanitary pads. As such, girls and young women's consumption practices are not only different in kind but also spatially distinct from the sites in which their male peers spend their senbeta misa money. These gendered consumption practices reinforce a broader gender pattern in which women's lives revolve to a greater extent around the home and men's lives take place in public places to a much greater extent. It is important to note that the spatial segregation of gendered leisure is also shaped by, as well as shaping, the division of reproductive labour (see also Abebe, 2007: 86-87). All the young female weavers reported being responsible for at least one reproductive task, such as cooking, making coffee, collecting firewood, looking after younger siblings, washing clothes and sewing. In contrast, none of the boys were confined by such additional reproductive chores in the household other than some occasional fetching of water and washing of clothes.

\section{Monetised leisure and age groups}

My friends receive senbeta misa on Sundays for their weaving work but I always left home with an empty pocket. They could buy whatever they wanted with their money, I could not do anything except watch them. When they enjoyed a sweet, I rubbed my dry mouth . . . So, I thought and asked myself why I didn't work and get money like my friends? I then started learning how to weave. (16-year-old male Gamo weaver: Addis Ababa, 18 September 2016)

Just like the 8 to 11-year-old children Bernadine Chee (2000: 54) worked with in Beijing, China, also among the young Gamo weavers hanging out with peers often centred around consumption practices in which independent control over money was key. Consumption must thus be recognised as an important aspect of leisure and a practice through which peer relations are formed and sustained (see also Zelizer, 2002: 389-390). However, in urban Ethiopia, too, leisure activities are seldom for free. This can be as basic as enjoying some sweets together as the excerpt above indicates.

Based on his research in rural Ethiopia, Tatek Abebe (2007: 86) observed that 'the monetization of a once subsistence economy' through the commercial production of coffee is eroding an agebased seniority system with the effect that 'fathers and elderly kinsmen seem to have less influence in making decisions about their children's everyday life'. This also holds for urban Ethiopia. Having their own money, boys and young men in particular have become independent consumers and become involved in activities over which their parents have little say. This is most evidently the case in their leisure activities.

We agree with Abebe that children's independent consumption practices may unsettle parentchild relations. Yet, we add that it strengthens age-based peer relations among younger and older boys. For example, the following two games requiring money were highly popular among young boys (roughly up to $12-13$ years):

- Playing marbles. To participate in this game requires a small investment of 0.25 birr to buy a single marble (biy).

- Playing with cards of European football players and Indian Bollywood stars. These cards come with purchasing a particular brand of chewing gum (sold at 2 birr). These cards are used in simple chance games. For this, two children (mostly boys) would simultaneously throw one card up in the air and see on which side it lands. If both cards land with the same side up, the cards go to the player who guessed this right.

Older children (roughly 14 years and older) considered these two activities childish and would avoid being seen playing these games. Instead, they would spend their leisure time chatting, 
Table I. Leisure activities of older boys.

\begin{tabular}{ll}
\hline Activity & Expense (in birr) \\
\hline A meal in a local restaurant & $10-20 \mathrm{birr}$ \\
Visiting a teashop & $3-10 \mathrm{birr}$ \\
Playing video games in a local venue & $3 \mathrm{birr} / \mathrm{game}$ \\
Watching movies in a local cinema & $5 \mathrm{birr} / \mathrm{movie}$ \\
Playing table football and betting & $50 \mathrm{cents} / \mathrm{game}$ \\
Collective saving practices and receiving money in rotation (lkub) & $10-100$ birr/week \\
\hline
\end{tabular}

Source: Field notes, 2016.

playing football, betting, frequenting local restaurants and teashops, playing video games and watching movies in local cinemas. As Table 1 indicates, these leisure activities are more costly than the activities younger boys engage in. The age-based distinction realised through such monetised forms of leisure reflects what Allison Pugh describes on the basis of her research in California; involving in certain forms of monetised leisure must be seen as enacting an age-based form of belonging by 'joining a peer or a group' (Pugh, 2011: 14).

The difference between leisure activities between older and younger children may indeed be in 'kind', and it may also be observed in 'intensity'. For example, watching European football matches in local cinemas is important for all boys and young men from the age of 8 or so. The entrance fee ranges from 2 to 5 birr depending on the teams which play and the venue. Whereas younger boys would watch such matches occasionally, for older boys, this was a regular activity. ${ }^{6}$ Watching these matches ties in with various other leisure activities revolving around football, ranging from collecting cards of football players mentioned above, playing football matches (and betting on them) as discussed below as well as being able to chat about football in an informed manner as explained by this 16-year-old male weaver:

During my spare time and right after school (late afternoon), I enjoy chatting with my friends, talking about sports news, the sale of key football players in the European Leagues and teasing friends who are fans of competing football clubs. (Interview notes: Addis Ababa, 20 September 2016)

We argue that through their leisure activities children enact a form of age-based distinction. No doubt, this is driven by changing tastes and desires with age yet achieving these distinctions requires money. Since older boys tend to receive a larger amount of senbeta misa than their younger peers (see Figure 1), the practice of senbeta misa facilitates boys and young men to enact age-based distinctions through monetised leisure activities. This echoes Daniel Thomas Cook's (2008: 235) point that children's identities and social position vis-à-vis other children often relates to their ability to consume. Yet, among the Gamo weavers, it is children's independent consumption thanks to senbeta misa which sustains this rather than their 'parental ability to pay' as Cook (2008) posits based on his research in North America.

The discussion above suggests that also in Ethiopia, 'modern childhood materializes through a global market' (Nayak and Kehily, 2013: 12) and that Ethiopian children, too, are 'born into regimes of consumption' (Cook, 2008: 236). This is evident from the many local cinemas targeting youth as well as chewing gum brands targeting children with cards of movie stars and football players. Yet, the power of market forces is neither all-determining, nor render children passive dopes. In fact, boys and young men actively contribute to the monetisation of their leisure activities. By this, we mean that children and youth integrate monetary elements into their leisure activities without necessarily being pushed to do so by market forces. To capture this dimension we have 
used the broader term monetisation in this article instead of commodification. Examples of boys and male youth's contribution to the monetisation of their leisure activities would include playing joteni (table football) for money or betting small amounts of money on joteni games.

Such child- and youth-driven monetisation of leisure activities transform the nature of the activity. Playing football is the case in point. Boys and male youth of all ages are involved in playing football. Yet it is by integrating a monetary dimension that a game of football becomes something different from just ordinary play. This may take the form of playing for money, setting up a competition with monetary prizes or betting on the results of the games. Talking with a 14-year-old weaver who regularly plays football games in which the winning team gains some money he explained that playing for money makes the game more exciting. The amounts played for usually range from 1 to 10 birr per match among younger boys. However, among older youth the amounts can be significantly larger. This is illustrated through the following conversation with a 15 -year-old weaver:

Fasil: How do you spend your senbeta misa?

Abate: I save it and spend it on football with my peers. We form a group of 15 persons (males) and save; when the money reaches around 2000 birr, we spend it on a football competition.

Fasil: Is it for betting?

Abate: The money is like a reward. There are rival teams and we play with them.

Fasil: How much money do you bet?

Abate: The stake is at least 1500 birr (approximately 68 Euros).

Fasil: Wow, that is a lot of money. What do you do if you win or lose?

Abate: When we win, we all go to a cafe and enjoy ourselves; when we lose, the winners do the same. (Interview dialogue: Addis Ababa, 25 February 2016)

\section{Conclusion}

Despite some notable exceptions (e.g. Katz, 2004; Wells, 2009), childhood research in the Global North and South remains driven by very different concerns and research priorities. This holds back the scope for meaningful dialogue across these wings of childhood research that, for example, Samantha Punch (2016) calls for. Following Zelizer (2002: 393), we would suggest that studying children's engagement with money, especially in relation to consumption for leisure purposes, constitutes a fertile area for bridging this divide. Admittedly, children's lives in the Global South, more so than that of their peers in the Global North, may be characterised by degrees of relative and absolute poverty. Nonetheless, in the Global South, too, childhoods have become monetised. In addition, consumption for leisure purposes is important among the poor too (Arora, 2019). For these reasons, in our research with young Gamo weavers in Addis Ababa, we have appreciated money and the leisure-related consumption it facilitates as a constituting dimension of what it means to be a child or a youth.

Following Zelizer (2002), we have shown that young people's consumption is shaped by and also shaping social relations. Among the Gamo weavers, this is evident from the way in which ethnicity, gender and age intersect in relation to access to money and the kind of consumption this enables. The practice of senbeta misa is particular to the weaving Gamo. As such, access to cash and the consumption this facilitates works as a form of distinction for Gamo childhoods. Yet, we have shown that senbeta misa is unevenly distributed among male and female Gamo children. We have argued that this is partly because of the gender division of labour in weaving, and also because of the very different ways in which money is associated with normative constructs of boyhood and girlhood. These latter dynamics also go some way in explaining the gendered differences in the 
spatiality and kind of consumption boys and girls participate in. We further argued that consumption also shapes age relations. It is through the kind and intensity of consumption that boys and young men enact belonging to age-based peer groups.

The particular case of the Gamo people in Ethiopia has shown that the modern phenomenon of a monetised childhood is among the Gamo at least six decades old and firmly rooted in a traditional apprenticeship system of learning to weave. This observation debunks discourses of crisis frequently associated with children's lives in the Global South and the idea that southern, and especially African, childhoods are somehow 'removed from forces of modernity, infrastructure and technology' (Abebe and Ofosu-Kusi, 2016: 304). While we have made the case for appreciating children and youth as social actors in relation to consumption we do recognise the powerful forces shaping the practice. Indeed, in the Global South, too, children and youth are targeted as an important segment in the consumer market (e.g. Huijsmans and Trân, 2015). In the context of urban Ethiopia, the targeting of children by commercial actors may take the form of, for example, chewing gum brands attracting young customers with cards of football players and Bollywood stars, as well as local cinemas screening European football matches that are popular among boys and young men. However, children and youth's consumption and the monetisation of childhood this results into is not a mere response to the tactics of commercial actors. We have argued that children and youth themselves also actively contribute to the monetisation of childhoods, for example, by adding a monetary dimension to their everyday games. Through these mundane monetary practices, children and youth change the nature of these games. In addition, practices like this should encourage childhood scholars in the Global South, too, to take seriously the role of money and consumption in understanding changing childhoods and youth.

\section{Funding}

The author(s) received no financial support for the research, authorship and/or publication of this article.

\section{ORCID iD}

Fasil Nigussie Taye iD https://orcid.org/0000-0002-1996-776X

\section{Notes}

1. In Amharic, the equivalent term to Sabbath is 'Senbet' and, according to the Ethiopian Orthodox church, this refers to the rise of Christ. However, 'senbet' is also frequently used to mean Sunday.

2. One of the main ethnic groups in Ethiopia.

3. For one female young weaver who received senbeta misa we do not have a weekly amount, hence $\mathrm{n}=35$. In a number of cases, young weavers reported various amounts of senbeta misa as the amount fluctuates based on the sales and other factors. In such cases we have used the average in Figure 1.

4. The exchange rate for 1 Euro was for approximately 22 birr during this period.

5. To put things into perspective: 50 birr would cover the entrance fee for watching around 15 European football games in the local cinema or youth centre.

6. While watching European football matches is a recent phenomenon, watching screened forms of popular culture has long been an important feature of a modern Ethiopian (masculine) youth. For example, a 44-year-old male weaver explained that in his youth he spent his senbeta misa, among other things, on watching Indian Bollywood and American Hollywood movies in a local cinema (video bet; Field notes: Addis Ababa, 21 September 2016).

\section{References}

Abebe T (2007) Changing livelihoods, changing childhoods: Patterns of children's work in rural Southern Ethiopia. Children's Geographies 5: 77-93. 
Abebe T and Ofosu-Kusi Y (2016) Beyond pluralizing African childhoods: Introduction. Childhood 23: 303-316.

Arora P (2019) The Next Billion Users: Digital Life Beyond the West. Cambridge, MA; London: Harvard University Press.

Billimoria J, Penner J and Knoote F (2013) Developing the next generation of economic citizens: Financial inclusion and education for children and youth. Entreprise Development and Microfinance 24: 204-217.

Chea L and Huijsmans R (2018) Rural youth and urban-based vocational training: Gender, space and aspiring to 'become someone'. Children's Geographies 16: 39-52.

Chee BWL (2000) Eating snacks, biting pressure: Only children in Beijing. In: Jing J (ed.) Feeding China's Little Emperors: Food, Children and Social Change. Stanford, CA: Stanford University Press, pp. 48-70.

Cook DT (2005) The dichotomous child in and of commercial culture. Childhood 12: 155-159.

Cook DT (2008) The missing child in consumption theory. Journal of Consumer Culture 8: 219-243.

Degefe B (1995) The development of money, monetary institutions and monetary policy (in Ethiopia), 194175. In: Bekele S (ed.) An Economic History of Ethiopia: The Imperial Era 1941-74. Dakar, Senegal: CODESRIA, pp. 234-240.

Huijsmans R (2016) Generationing development: An introduction. In: Huijsmans R (ed.) Generationing Development: A Relational Approach to Children, Youth and Development. London: Palgrave Macmillan, pp. 1-31.

Huijsmans R (2019) Becoming mobile and growing up: A 'generationed' perspective on borderland mobilities, youth, and the household. Population, Space and Place 25: 1-10.

Huijsmans R and Trân THL (2015) Enacting nationalism through youthful mobilities? Youth, mobile phones and digital capitalism in a Lao-Vietnamese borderland. Nations and Nationalism 21: 209-229.

Jirata TJ (2019) The cultural spaces of young children: Care, play and learning patterns in early childhood among the Guji people of Ethiopia. Global Studies of Childhood 9: 42-55.

Katz C (2004) Growing Up Global: Economic Restructuring and Children's Everyday Lives. Minneapolis, MN; London: University of Minnesota Press.

Levison D (2000) Children as economic agents. Feminist Economics 6: 125-134.

Nayak A and Kehily MJ (2013) Gender, Youth \& Culture: Global Masculinities \& Femininities. 2nd ed. Basingstoke: Palgrave Macmillan.

Pugh AJ (2011) Distinction, boundaries or bridges? Children, inequality and the uses of consumer culture. Poetics 39: 1-18.

Punch S (2016) Cross-world and cross-disciplinary dialogue: A more integrated, global approach to childhood studies. Global Studies of Childhood 6: 352-364.

Ruckenstein M (2010) Time scales of consumption: Children, money and transactional orders. Journal of Consumer Culture 10: 383-404.

Taye FN (2019) Changing childhoods, places and work: The everyday politics of learning-by-doing in the urban weaving economy in Ethiopia. PhD Thesis, International Institute of Social Studies, Erasmus University Rotterdam, The Hague.

Wells K (2009) Childhood in a Global Perspective. Cambridge; Malden, MA: Polity Press.

White B (1996) Globalization and the child labour problem. Journal of International Development 8: $829-839$.

Woodhead M (1999) Combatting child labour: Listen to what the children say. Childhood 6: 27-49.

Zelizer V (2002) Kids and commerce. Childhood 9: 375-396.

\section{Author biographies}

Fasil Nigussie Taye is assistant professor of Social Work and Development at the Addis Ababa University, School of Social Work. His research combines global and local childhood approaches, focusing on children and youth in a development context.

Roy Huijsmans is associate professor of Childhood and Youth Studies. He has published on topics such as conceptualising age and generation, child and youth migration, as well as the intersection between young people's mobile phone use and nationalism. 